This item was submitted to Loughborough's Research Repository by the author.

Items in Figshare are protected by copyright, with all rights reserved, unless otherwise indicated.

\title{
Approaches to displaying information to assist decisions under uncertainty
}

PLEASE CITE THE PUBLISHED VERSION

http://dx.doi.org/10.1016/j.omega.2011.05.010

PUBLISHER

(c) Elsevier

VERSION

AM (Accepted Manuscript)

LICENCE

CC BY-NC-ND 4.0

REPOSITORY RECORD

Kreye, Melanie E., Yee M. Goh, Linda B. Newnes, and P. Goodwin. 2019. "Approaches to Displaying Information to Assist Decisions Under Uncertainty”. figshare. https://hdl.handle.net/2134/10699. 
This item was submitted to Loughborough's Institutional Repository (https://dspace.lboro.ac.uk/) by the author and is made available under the following Creative Commons Licence conditions.

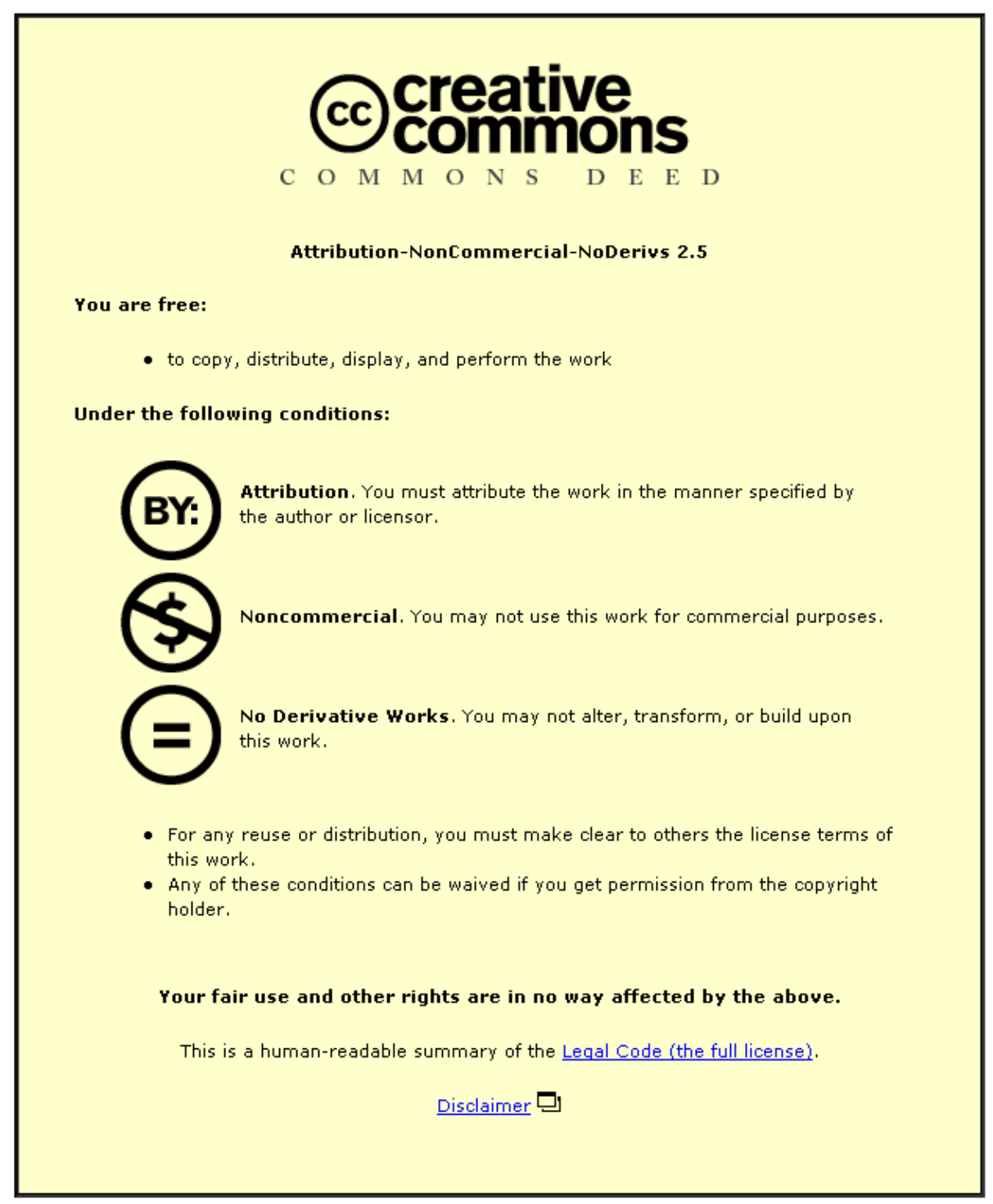

For the full text of this licence, please go to: http://creativecommons.org/licenses/by-nc-nd/2.5/ 


\title{
Approaches to Displaying Information to Assist Decisions under Uncertainty
}

\author{
M.E. Kreye*, Y.M. Goh ${ }^{\dagger}$, L.B. Newnes ${ }^{\ddagger}$, P. Goodwin ${ }^{\S}$
}

\begin{abstract}
The estimation of the costs of a product or project and the decisions based on these forecasts are subject to much uncertainty relating to factors like unknown future developments. This has been addressed repeatedly in research studies focusing on different aspects of uncertainty; unfortunately, this interest has not yet been adopted in practice. One reason can be found in the inadequate representation of uncertainty. This paper introduces an experiment which engages different approaches to displaying cost forecasting information to gauge the consideration of uncertainty in the subsequent decision-making process. Three different approaches of displaying cost-forecasting information including the uncertainty involved in the data were tested, namely a three point trend forecast, a bar chart and a FAN-diagram. Furthermore, the effects of using different levels of contextual information about the decision problem were examined. The results show that decision makers tend to simplify the level of uncertainty from a possible range of future outcomes to the limited form of a point estimate. Furthermore, the contextual information made the participants more aware of uncertainty. In addition, the fan-diagram prompted $75.0 \%$ of the participants to consider uncertainty even if they had not used this type of diagram before; it was therefore identified as the most suitable method of graphical information display for encouraging decision makers to consider the uncertainty in cost forecasting.
\end{abstract}

Keywords: Uncertainty, cost forecasting, decision making

\section{Introduction}

Uncertainty influences most business decisions [1], shapes the way people interact with each other [2], exists in the material properties of physical systems [3], and is directly related to the performance of a product [4]. Because of its importance it has been the focus of research in a range of areas such as design, economics [5-7], and particularly cost estimation and forecasting [8-10]. Estimating costs, especially in the early design phases, involves uncertainty about possible future developments and decisions. The importance of considering uncertainty in these areas has been highlighted by researchers and approaches for modelling and treating it have been developed [11$14]$.

However, the practical adoption of the management of uncertainty does not reflect this research development [2]. Discussions with industry-based cost estimation experts during conferences and other venues have shown that the consideration of uncertainty is underrepresented in industry,

\footnotetext{
* Corresponding author; Department of Mechanical Engineering, University of Bath, Claverton Down, Bath, BA2 7AY, UK. Email: M.Kreye@bath.ac.uk, Tel: +44 (0)1225 385366.

${ }^{\dagger}$ Wolfson School of Mechanical and Manufacturing Engineering, Loughborough University, Loughborough, Leicestershire, LE11 3TU, UK.

\$Department of Mechanical Engineering, University of Bath, Claverton Down, Bath, BA2 7AY, UK.

$\S$ School of Management, University of Bath, Claverton Down, Bath, BA2 7AY, UK.
} 
especially where decisions have to be made [15]. Even when uncertainty is considered in the information-capturing process it is rarely included in the final decision [16-18]. Given a distribution of possible outcome scenarios, decision makers tend to choose the average or simply the most likely value which often results in an overconfident and inaccurate decision [1]. One of the main reasons for this neglect is the inadequate representation of uncertainty in the information supplied to decision makers. A clear representation of input information is essential to support an informed decision [18-20]. This suggests that an adequate representation of the uncertainty associated with the data and the future outcome of a decision will enhance the consideration of uncertainty in decision making.

This paper describes how the decision maker understands and interprets the uncertainty included in a cost forecast and how this interpretation changes with different ways of representing the information. An experiment is introduced which tested the effects of differently displayed representations of the uncertainty on the decision maker's understanding of the problem. The state of the art in uncertainty research is described in Section 2.

\section{Uncertainty in research}

Many authors have suggested that there is a difference between risk and uncertainty [21, 22], but, different definitions and classifications of risk and uncertainty can be found in literature [13, 14, 2325]. Nevertheless, the terms uncertainty and risk are still used interchangeably to describe similar problems in practice. The definitions applied to the research presented in this paper are as follows. Uncertainty is defined as something that is not definite, not known or not reliable which results in a potential deficiency in any phase or activity of the process [26, 27]. This means that some relevant information about the outcome of a process or a decision in the future is not known or knowable [2]. Risk can be defined as the possible impact or outcome of this uncertain situation or problem [28]. This research focuses on uncertainty and, thus, does not discuss risk in any more detail.

Describing uncertainty research, a distinction has to be made between the general concept of uncertainty in its nominal existence in a situation and the concept that is connected to a person in the sense of making him/her feel unsure or unconfident. A particular situation can have an inherent uncertainty, for example the costs of a particular material cannot be forecasted exactly but only as an interval. In contrast, a decision maker facing this uncertainty may feel very confident about basing his/her decision on a specific cost value depending on e.g. his/her experience. The presented research comprehends uncertainty as an independent concept and aims at the decision maker's accurate understanding and interpretation of this uncertainty.

Uncertainty can be categorised as quantitative and qualitative by expression. Quantitative describes the uncertainties that can be measured e.g. in numbers [25]. It has been the topic of many research papers over the decades especially in the area of modelling uncertainty using probability theory [2932]. Qualitative uncertainties have largely been unaddressed in past research [13, 25]; and, given their nature, are mostly associated with the societal aspect of a problem such as the framing of the problem, model structures, system boundaries, and judgement [33]. Uncertainty modelling in cost estimation usually deals with quantitative uncertainty or numbers that have been allocated to qualitative uncertainty [34-36]. The uncertainty is typically included in the cost forecast as a range of possible outcomes. Using number allocation, numbers (or intervals) are allocated to the 
qualitative uncertainties and then included in the cost model [37]. For example in fuzzy set theory, a value is allocated to qualitative information according to its affiliation to a membership function [38-40]. These uncertainties can be considered and included in a cost forecast and a cost forecast display.

One important research area is the perception and interpretation of the uncertainty included in the cost forecast. Psychology research has investigated how people experience the existence of uncertainty and how they react. Two different reactions were identified: for some, the situation was overwhelming and they felt paralysed, for others, the situation encouraged them and they found new solutions and answers [41]. The researchers concluded that the difference was created by the perception of "controlling" the uncertainty. When a situation offers a high level of control, individuals can feel more intrinsic motivation and show more initiative caused by the experience of psychological factors such as greater interest, less pressure, more creativity, and a higher selfesteem $[42,43]$. If a situation offers a low level of control, these positive outcomes are less likely to occur [44]. These reactions are very subjective and depend on the characteristics and experience of the specific person [45].

Decision makers tend to ignore uncertainty and in particular, they tend to avoid the possible negative impact of uncertainty [46, 47]. Their reactions to the possibilities of regret and disappointment have been discussed in this context [48-51]. Other reactions that can be observed, particularly after the outcome of a decision problem has become reality, include the invention of a "higher rationale" to explain uncertain events and so treat them as if they involved the skills of the decision maker and, therefore, seem influenceable and controllable [46, 52, 53]. Experiments in this area have been described as the throwing of dice where the gamblers were observed to throw the dice with greater force in order to throw a higher number [52], the prediction of coin tosses where students perceived themselves as "better than the average" predictors of outcomes when they made correct predictions at the beginning of the experiment [54], and the winning of a lottery where the participants assigned higher confidence in having the winning lottery ticket when they had chosen the ticket themselves as opposed to receiving a randomly allocated one [46, p. 257].

If decision makers do acknowledge the presence of uncertainty in the decision process, for example via a forecast range, they tend to underestimate it, or in other words, they overestimate the probability that the range will include the true outcome $[55,56]$. A so-called surprise index indicates what percentage of true values out of a number of given estimates fall outside the range expressed by the tested person. For example, for a $90 \%$ confidence interval this percentage should be $10 \%$. If the observed percentage exceeds this value, the individual is overconfident. In contrast, if less than $10 \%$ of outcomes occur outside the interval this would indicate that the person is underconfident (i.e. their interval is too wide). Many studies which have investigated the assessment of uncertain parameters have found that forecasters tend to be overconfident [55, 57-60]. Even after the tested participants were confronted with their overconfidence and asked to give a new estimate, they improved but were still considerably overconfident [57, 61, 62]. Different explanations for these phenomena have been found. However, the one of which has received the most attention is the idea that decision makers use an "anchor-and-adjust" heuristic for estimating a range of possible values $[63,64]$. That means that they use their belief of the most likely value as an anchor and set the boundaries of the range or interval by adjusting away from that value. Within this procedure, they make too small an adjustment from the anchor and hence of the range width is too small [55, 63-65].

Nevertheless, some studies have found that, under some circumstances uncertainty is overestimated [63, 66-68]. For example, in a study by Bolger and Harvey [66], decision makers were asked to estimate the probability of the future value in a time-series being below a given reference point and compared the answers to the true probabilities. The study found that the probabilities of less than 
$50 \%$ were overestimated and those of more than $50 \%$ were underestimated. Similarly, Diebold et al. [67] found that forecasters overestimated the probability of the future value of inflation falling below a stated point forecast. Both research studies involved the estimation of uncertainty relative to a reference point which suggests that uncertainty assessment is sensitive to the methods used to obtain the estimates.

This sensitivity suggests that well calibrated prediction intervals might be obtained by distributing the forecasting problem to two experts. One would be asked to give a range within which the future value is supposed to fall and the other would then be asked to estimate a probability value for this range [63]. However, this is clearly not an option when, only one person is responsible for an entire decision.

In the case of overconfident decision makers, contradictory evidence has been found on the influence of additional information or knowledge on the estimation of uncertainty. Pickard and Wallace [62] tested the influence of training on the overconfidence of the decision makers by giving them immediate feedback throughout five and six sessions of forecasting for the same problem. The results showed a moderate improvement (a 37.5\% reduction of the surprise index for five sessions and a $47.8 \%$ reduction of the surprise index for six sessions) but there still remained a high level of overconfidence. O'Connor and Lawrence [59] revealed that the provision of feedback to people on the accuracy of their forecasts improved the calibration of future confidence intervals considerably, especially when a confidence interval of $75 \%$ was requested. Other studies, on the other hand, show contradictory evidence. Brown [69] studied the effect of additional information in the form of extensive historical data while Lichtenstein and Fischhoff [70] studied the impact of calibration training on the surprise index of forecasters. Both results show no improvement in the estimation of uncertainty.

The uncertainty connected to an event or the outcome of a decision can be assessed through a subjective probabilities which typically represent degrees of belief [71]. This expresses the decision maker's (subjective) belief about the likelihood of an uncertain event happening or of an uncertain outcome of a process [72]. This belief can be expressed in a number of ways including the use of phrases such as "It is likely that" or "Highly improbable that" which may be ambiguous [73]. This belief function is affected by a number of influences such as the biases of the decision maker or the decision maker's experience which can lead to over or underestimation of the probability of the outcome. These subjective probabilities cannot usually be judged as "right" or "wrong" [55, 71]; they can be judged, however, on their level of realism (e.g. see Lichtenstein et al. [55]). In the experiment that is described in Section 3, the subjective beliefs in the likelihood of propositions are represented as confidence levels.

When the assessment of a forecasting problem is dependent on the judgement of the decision maker, it is subjective which means that it is likely to be biased and inconsistent [63]. Examples of biases include the underestimation of trends or the over influence of recent events [74, 75]. Recent events can cause the probability of a forthcoming similar event to be either over or underestimated. Overestimation can result from the use of the availability heuristic [76]. This was observed in the context of earthquake insurances in California after the earthquake in 1989, when the number of sold policies increased significantly [77]. Underestimation can result from the gambler's fallacy [76].

The general ignorance of uncertainty in the decision process and the biases associated with this can lead to a misinterpretation of situations and wrong decisions [47, 78, 79]. However, the consideration of uncertainty in cost estimation and forecasting has not yet been addressed. One major aspect in the cost estimation and forecasting process is the collection and interpretation of relevant information. Graphical displays of this information are common and can be seen as an important communication channel to improve a decision maker's comprehension of the problem at 
hand [19, 20, 74]. However, different graphs displaying the same information point the viewer towards different aspects of the information [80]. Therefore, displaying uncertain forecasts in different ways is likely to change the decision maker's perception of the information and so influence which aspects are included in the decision process. Section 3 introduces an experiment that was designed to test the relative effectiveness of different approaches to displaying cost forecasting information in terms of their ability to encourage decision makers to consider uncertainty in their decisions.

\section{Including uncertainty in decisions - a practical analysis}

The experiment presented in this paper was constructed to test how the decision maker understands and interprets the uncertainty included in a cost forecast. Earlier, the influence of the subjective judgement of the decision maker was highlighted as being influential on the forecasting [81-83]. For this experiment the three key types of judgement identified were investigated. These were the use of judgement:

- to extrapolate information on past series into the future,

- to adjust statistical time series extrapolations, and

- to integrate both time series and contextual information [81] to produce a cost forecast.

To investigate the decisions taken, it was necessary to identify the types of information typically available in a forecasting process. This includes time series information, labels and contextual information. Time series represent past information recorded at different points in time, such as the past development costs of a product. Labels are the representations of the variable that is being forecast, for example the vertical axis of a graph may be labelled as 'monthly costs, \$'. Contextual information gives further background on the estimation problem. For example, it may contain details of special circumstances that may cause a trend in costs to be disturbed.

\subsection{Aim of the experiment}

Presenting information in a graphical display can result in an improved understanding of data compared with using only textual or tabular information [19, 20, 63, 80, 84]. In the light of these findings the experiment focused on analysing people's propensity to consider uncertainty as a result of seeing different graphical displays. The overall aim of the experiment was to ascertain the most appropriate way of displaying the uncertainty involved in a forecasting problem. The two research questions investigated were;

1) What type of graphical display is required to assist the decision maker in considering uncertainty?

2) How much contextual information is required to represent uncertainty in the decisionmaking process?

An experiment was used to address these questions.

\subsection{Experiment procedure}

The experiment was carried out at a one day conference on "Cost Estimating for Defence Programmes" organised by the Society for Cost Analysis and Forecasting (SCAF) which was attended by costing experts from the aerospace and defence sectors. The experiment consisted of two questionnaires, each included a set of questions which were presented in a predetermined order [85]. To reduce the likelihood of the participants remembering what they selected in questionnaire 
1, questionnaire 2 was completed after a defined time difference. The first questionnaire was handed out and collected early in the morning at the conference and the second one in the afternoon.

In order to test different ways of displaying information, the participants were divided into three groups $\mathrm{A}, \mathrm{B}$, and $\mathrm{C}$. The affiliation to a certain group was allocated randomly. The participants stayed in their groups throughout the whole experiment so somebody who answered questionnaire 1 from group A would also answer questionnaire 2 for that group. For each of the groups, different graphical displays were used to represent the forecasts as shown in Figure 1. These graphical displays were;

- a three point trend forecast for group A,

- a bar chart with minimum, medium and maximum estimates for group B, and

- a fan diagram for group C.

Each of the graphs displayed past data on the monthly cost of a raw material from January 1990 to January 2009, together with the forecasts. It consisted of the same information and labels providing a forecast scenario with minimum, medium and maximum values. The cost data was artificially generated so that the observations were distributed randomly around a linear upward, 'flat' or downward trend.

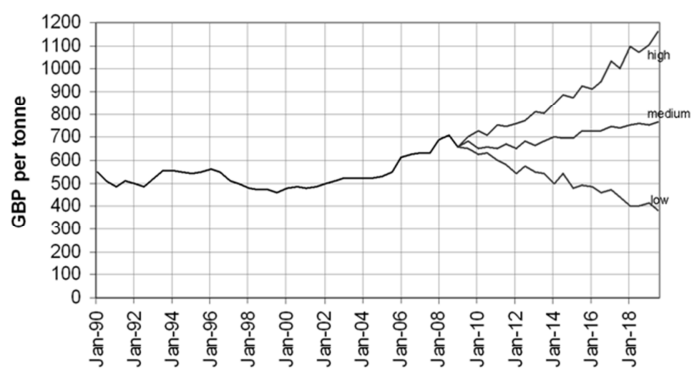

Group A

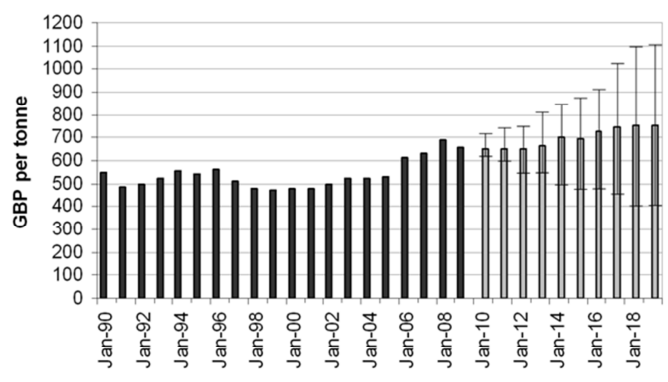

Group B

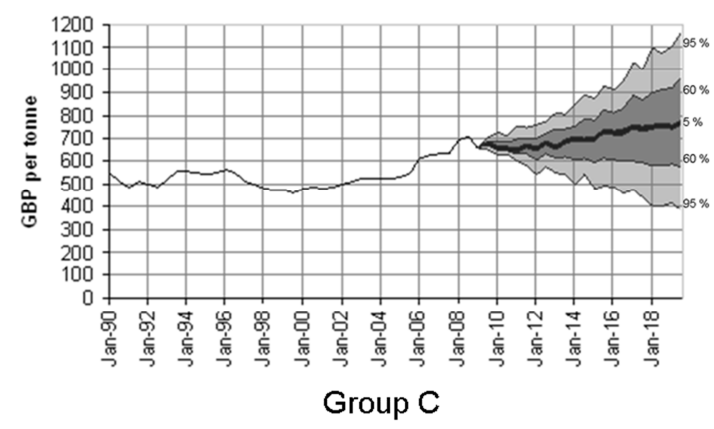

Figure 1: Graphical display of the forecasting problem

Both questionnaires contained the same forecasting scenario and contained six questions.

- First, participants were asked to give an estimate of the future costs of the raw material for the year 2014 (January), based on the information given. The choice of giving a point or interval estimate was left to the participants.

- Then, they were requested to give the reasons for their answer; this was phrased as an open question. 
- Finally, they were asked to provide the confidence level for their estimate. Six discrete intervals were given between which the participants could choose. Those were $0-20 \%, 21-40 \%, 41-50 \%$, $51-60 \%, 61-80 \%$, and $81-100 \%$. It should be noted that a statement of confidence in relation to a point forecast of a continuous variable is ambiguous since the theoretical probability that the forecast will equal the outcome is zero. However, this question gave an insight on the extent to which people are prepared to make such ambiguous statements when estimating future values of an uncertain variable.

The same questions were asked in order to obtain an estimate of costs for 2018 (Questionnaire 2). The two questionnaires differed in the amount of information that was supplied:

- Questionnaire 1 only gave some general information on the forecasting problem and a graph with the historical and estimated future prices of the raw material.

- Questionnaire 2 included more detailed information relating to the forecast, e.g. what the different values meant and the assumptions that underpinned the forecasts. The additional information focused on the background of the graphical information. It was kept to a basic level as people are constrained in the amount of information they can consider and process in a decision making process [86-88].

The next section describes the participants and their characteristics.

\subsection{Participants}

The participants were cost engineers from industry part-taking in a cost estimation workshop organised by the Society for Cost Analysis and Forecasting (SCAF). Forty-four experts (out of 52 attendees at the conference) participated in the experiment of which 13 were assigned to group A, 15 to B and 16 to C. $75 \%$ of participants stated that they had worked before with a diagram of the same type that was presented to them in the experiment and $40 \%$ said they had used it in cost estimation, albeit with differing frequencies. Of the people who had used that type of graph in their work, $13 \%$ stated that they used it once a week, $27 \%$ once a month, $20 \%$ once every other month, $20 \%$ once a year and $20 \%$ used it only occasionally. Table 1 summarises the results per group in terms of familiarity with the diagram in the questionnaire and whether they had used the type of diagram in their work. The table shows both the absolute number of participants and the percentage. For groups A and C, these percentages do not add up to $100 \%$ because two participants in each group did not reply to these questions.

The results show that the participants of group A (who were presented with the three point graph) had the highest level of familiarity with the graph they were given and also the highest level of experience of working with this type of graph. Those in group $\mathrm{C}$ (who were presented with a fan chart) had the lowest levels of familiarity and experience with the graph they were given. The assignment of participants to the groups was as follows:

- Group A: 13 participants (10 experienced),

- Group B: 15 participants (12 experienced),

- Group C: 16 participants ( 9 experienced). 
Table 1: Participants' experience with diagram according to the groups

\begin{tabular}{|l|c|c|c|c|c|c|c|c|c|}
\hline \multirow{2}{*}{ Question } & \multicolumn{3}{|c|}{ Group A } & \multicolumn{3}{c|}{ Group B } & \multicolumn{3}{c|}{ Group C } \\
\cline { 2 - 10 } & Yes & No & $\begin{array}{c}\text { Y/N- } \\
\text { Ratio }\end{array}$ & Yes & No & $\begin{array}{c}\text { Y/N- } \\
\text { Ratio }\end{array}$ & Yes & No & $\begin{array}{c}\text { Y/N- } \\
\text { Ratio }\end{array}$ \\
\hline $\begin{array}{l}\text { Have you seen a } \\
\text { diagram like this } \\
\text { before? }\end{array}$ & $\begin{array}{c}10 * \\
76.9 \%\end{array}$ & $\begin{array}{c}1 * \\
7.7 \%\end{array}$ & $\mathbf{1 0 . 0}$ & $\begin{array}{c}12 \\
80.0 \%\end{array}$ & $\begin{array}{c}3 \\
20.0 \%\end{array}$ & $\mathbf{4}$ & $\begin{array}{c}9 * \\
56.3 \%\end{array}$ & $\begin{array}{c}5 * \\
31.2 \%\end{array}$ & $\mathbf{1 . 8}$ \\
\hline $\begin{array}{l}\text { Do you use this type of } \\
\text { diagram in your work? }\end{array}$ & $\begin{array}{c}7 * \\
53.9 \%\end{array}$ & $\begin{array}{c}4 * \\
30.8 \%\end{array}$ & $\mathbf{1 . 7 5}$ & $\begin{array}{c}5 \\
33.3 \%\end{array}$ & $\begin{array}{c}10 \\
66.7 \%\end{array}$ & $\mathbf{0 . 5}$ & $\begin{array}{c}4 * \\
25.0 \%\end{array}$ & $\begin{array}{c}10 * \\
62.5 \%\end{array}$ & $\mathbf{0 . 4}$ \\
\hline
\end{tabular}

* these figures do not sum to $100 \%$ because one participant failed to supply a forecast

This categorisation of the participants is maintained throughout the analysis of the results.

\section{Results}

In this section, the results of the experiment are analysed and explained in terms of the contextual information, the type of diagram used to display the information and the reasons given for selection of the estimate.

\subsection{Cost forecasts}

A first indication of the participants' understanding of uncertainty can be found in the kind of forecast that was elicited from them. If a range of possible outcomes was given, it was assumed that the decision maker was aware of the uncertainty connected to the cost forecasts. The following responses were interpreted as range forecasts: i) a three point forecast, ii) a range between a minimum and a maximum value and iii) uncertainty included in a narrative way, e.g. "around £700" or "approximately $£ 700$ ". Table 2 shows the results for all the participants with those for the experienced subset of participants in brackets.

The results for the whole set of participants show no significant difference between the groups $(p<0.05)$. However, for the experienced participants, a difference can be observed for group C questionnaire 2. In this group, a range forecast was more usual than in the other two groups. This can be interpreted as the increased awareness of uncertainty that is caused by the fan diagram in combination with further contextual information. As stated, these results may provide an indication of the reduced level of confidence provided by the participants in this group.

For all three groups, some forecasts stated as a range in 2014 were reduced to a point forecast in 2018. In general, an event further into the future will be subject to more uncertainty which means that the range estimate for 2014 should change to an even larger range in 2018. The difference between the theoretical explanation and the practical observation can possibly be explained with the subjective perception that an event which is a long way into can be perceived as less uncertain because disturbances caused by short term incidents will not spread as far as that.

The forecasts produced by the participants were assigned to one of five categories ranging from low to high based on their position in the graphical display. Figure 2 shows the percentage of forecasts in each category for both the 2014 and 2018 forecasts made in response to questionnaires 1 and 2. If a range forecast was given, it was classified as either "low $<$ medium" or "medium $<$ high" depending on which side of the graph it was taken from. There were no significant differences in the forecasts produced by those who were experienced in using the type of graph supplied and those who were not experienced. Thus, Figure 2 displays forecasts for the whole set of participants. 
Table 2: Summary of given answers for each group and each questionnaire

\begin{tabular}{|l|l|c|c|c|c|}
\hline & Questionnaire & \multicolumn{2}{|c|}{$\mathbf{1}$} & \multicolumn{2}{|c|}{$\mathbf{2}$} \\
\cline { 2 - 6 } & Year & $\mathbf{2 0 1 4}$ & $\mathbf{2 0 1 8}$ & $\mathbf{2 0 1 4}$ & $\mathbf{2 0 1 8}$ \\
\hline \multirow{4}{*}{ Group A } & range forecast & $7.7 \%$ & $7.7 \%$ & 0 & 0 \\
& quoted & $(10.0 \%)$ & $(10.0 \%)$ & $(0)$ & $(0)$ \\
\cline { 2 - 6 } & point forecast & $92.3 \%$ & $92.3 \%$ & $100 \%$ & $100 \%$ \\
& quoted & $(90.0 \%)$ & $(90.0 \%)$ & $(100 \%)$ & $(100 \%)$ \\
\hline \multirow{4}{*}{ Group B } & range forecast & $20.0 \%$ & $7.1 \%$ & $7.1 \%$ & 0 \\
& quoted & $(25.0 \%)$ & $(8.3 \%)$ & $(8.3 \%)$ & $(0)$ \\
\cline { 2 - 6 } & point forecast & $80.0 \%$ & $92.9 \%$ & $92.9 \%$ & $100 \%$ \\
& quoted & $(75.0 \%)$ & $(91.7 \%)$ & $(91.7 \%)$ & $(100 \%)$ \\
\hline \multirow{5}{*}{ Group C } & range forecast & $25.0 \% *$ & $12.5 *$ & $25.0 \%$ & $25.0 \%$ \\
& quoted & $(33.3 \%)$ & $(22.2 \%)$ & $(33.3 \%)$ & $(33.3 \%)$ \\
\cline { 2 - 6 } & point forecast & $68.8 \% *$ & $81.3 \% *$ & $75.0 \%$ & $75.0 \%$ \\
& quoted & $(66.7 \%)$ & $(77.8 \%)$ & $(66.7 \%)$ & $(66.7 \%)$ \\
\hline
\end{tabular}

* these figures do not sum to $100 \%$ because one participant failed to supply a forecast 


\section{Group A}
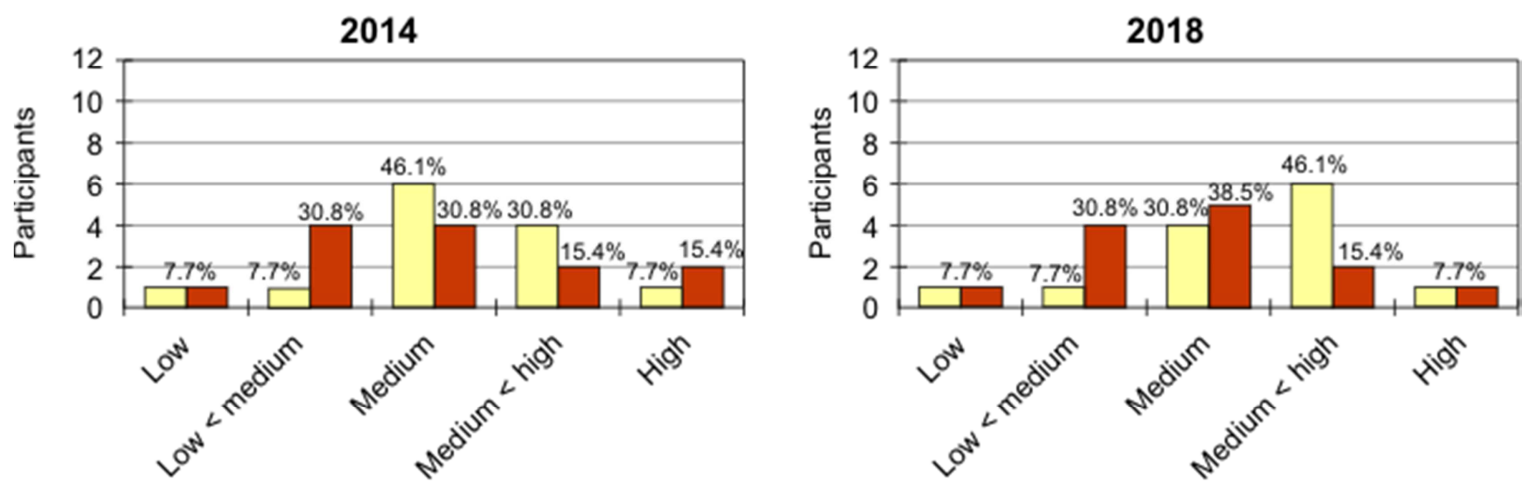

\section{Group B}
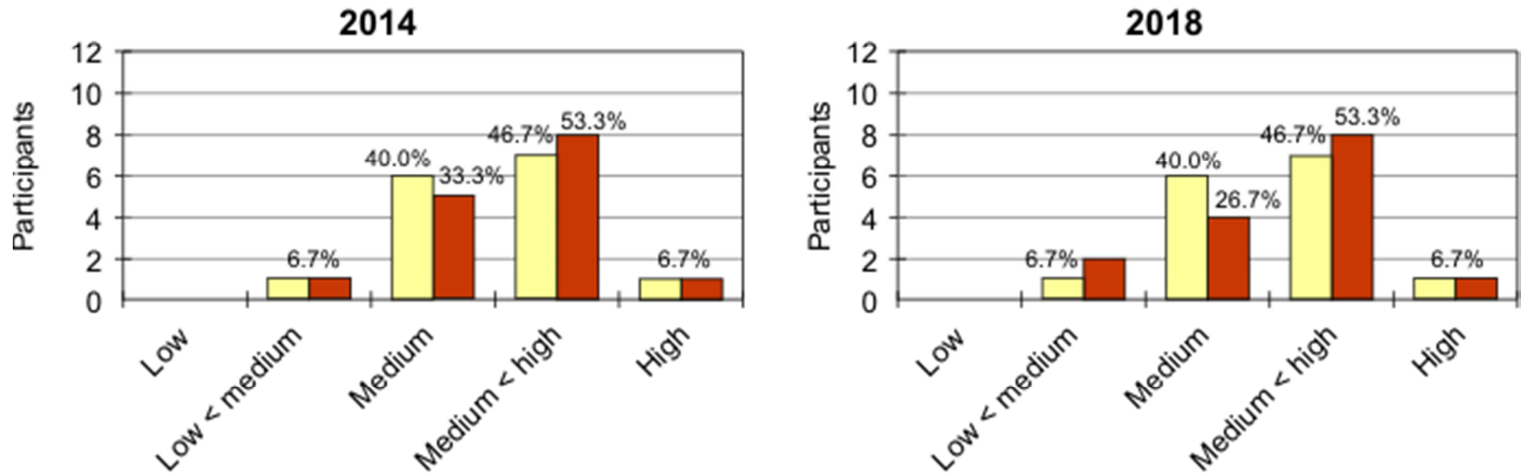

Group C
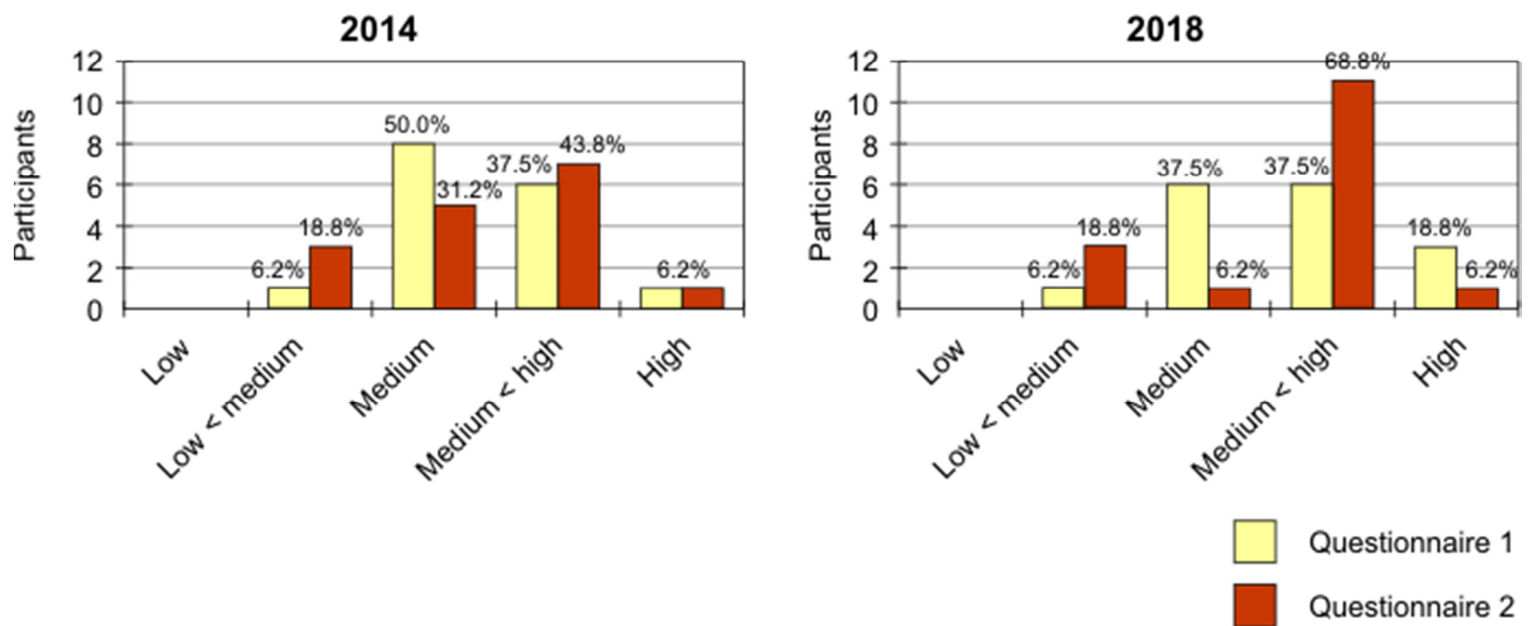

Figure 2: Forecasting values by each group in comparison

Table 3 shows the frequency of answers as the absolute value and the percentage for the all the participants and for the experienced participants in brackets. 
Table 3: Forecasting values by group in comparison between whole set and experienced subset of participants

\begin{tabular}{|c|c|c|c|c|c|}
\hline & \multirow{2}{*}{$\begin{array}{l}\text { Year } \\
\text { Questionnaire }\end{array}$} & \multicolumn{2}{|c|}{2014} & \multicolumn{2}{|c|}{2018} \\
\hline & & 1 & 2 & 1 & 2 \\
\hline \multirow{5}{*}{ Group A* } & Low & $\begin{array}{c}7.7 \% \\
(10.0 \%) \\
\end{array}$ & $\begin{array}{c}7.7 \% \\
(10.0 \%) \\
\end{array}$ & $\begin{array}{c}7.7 \% \\
(10.0 \%) \\
\end{array}$ & $\begin{array}{c}7.7 \% \\
(10.0 \%) \\
\end{array}$ \\
\hline & Low $<$ medium & $\begin{array}{c}7.7 \% \\
(10.0 \%)\end{array}$ & $\begin{array}{c}30.8 \% \\
(30.0 \%)\end{array}$ & $\begin{array}{c}7.7 \% \\
(10.0 \%)\end{array}$ & $\begin{array}{c}30.8 \% \\
(20.0 \%)\end{array}$ \\
\hline & Medium & $\begin{array}{c}46.1 \% \\
(50.0 \%)\end{array}$ & $\begin{array}{c}30.8 \% \\
(30.0 \%) \\
\end{array}$ & $\begin{array}{c}30.8 \% \\
(30.0 \%) \\
\end{array}$ & $\begin{array}{c}38.5 \% \\
(40.0 \%) \\
\end{array}$ \\
\hline & $\begin{array}{l}\text { Medium < } \\
\text { high }\end{array}$ & $\begin{array}{c}30.8 \% \\
(20.0 \%) \\
\end{array}$ & $\begin{array}{c}15.4 \% \\
(10.0 \%)) \\
\end{array}$ & $\begin{array}{c}46.1 \% \\
(40.0 \%)\end{array}$ & $\begin{array}{l}15.4 \% \\
(20.0 \%) \\
\end{array}$ \\
\hline & High & $\begin{array}{c}7.7 \% \\
(10.0 \%) \\
\end{array}$ & $\begin{array}{c}15.4 \% \\
(20.0 \%) \\
\end{array}$ & $\begin{array}{c}7.7 \% \\
(10.0 \%) \\
\end{array}$ & $\begin{array}{c}7.7 \% \\
(10.0 \%) \\
\end{array}$ \\
\hline \multirow{5}{*}{ Group B } & Low & $\begin{array}{c}0 \\
(0) \\
\end{array}$ & $\begin{array}{c}0 \\
(0) \\
\end{array}$ & $\begin{array}{c}0 \\
(0) \\
\end{array}$ & $\begin{array}{c}0 \\
(0) \\
\end{array}$ \\
\hline & Low $<$ medium & $\begin{array}{c}6.7 \% \\
(0) \\
\end{array}$ & $\begin{array}{c}6.7 \% \\
(8.3 \%) \\
\end{array}$ & $\begin{array}{c}6.7 \% \\
(0) \\
\end{array}$ & $\begin{array}{c}13.3 \% \\
(16.7 \%) \\
\end{array}$ \\
\hline & Medium & $\begin{array}{c}40.0 \% \\
(41.7 \%) \\
\end{array}$ & $\begin{array}{c}33.3 \% \\
(25.0 \%) \\
\end{array}$ & $\begin{array}{c}40.0 \% \\
(41.7 \%)\end{array}$ & $\begin{array}{c}26.7 \% \\
(25.0 \%) \\
\end{array}$ \\
\hline & $\begin{array}{l}\text { Medium < } \\
\text { high }\end{array}$ & $\begin{array}{c}46.7 \% \\
(50.0 \%)\end{array}$ & $\begin{array}{c}53.3 \% \\
(58.3 \%) \\
\end{array}$ & $\begin{array}{c}46.7 \% \\
(50.0 \%) \\
\end{array}$ & $\begin{array}{c}53.3 \% \\
(50.0 \%) \\
\end{array}$ \\
\hline & High & $\begin{array}{c}6.7 \% \\
(8.3 \%) \\
\end{array}$ & $\begin{array}{c}6.7 \% \\
(8.3 \%) \\
\end{array}$ & $\begin{array}{c}6.7 \% \\
(8.3 \%) \\
\end{array}$ & $\begin{array}{c}6.7 \% \\
(8.3 \%) \\
\end{array}$ \\
\hline \multirow{5}{*}{ Group $\mathbf{C}^{\dagger}$} & Low & $\begin{array}{c}0 \\
(0) \\
\end{array}$ & $\begin{array}{c}0 \\
(0) \\
\end{array}$ & $\begin{array}{c}0 \\
(0) \\
\end{array}$ & $\begin{array}{c}0 \\
(0) \\
\end{array}$ \\
\hline & Low $<$ medium & $\begin{array}{c}6.2 \% \\
(0) \\
\end{array}$ & $\begin{array}{c}18.8 \% \\
(22.2 \%) \\
\end{array}$ & $\begin{array}{c}6.2 \% \\
(0) \\
\end{array}$ & $\begin{array}{c}18.8 \% \\
(11.1 \%) \\
\end{array}$ \\
\hline & Medium & $\begin{array}{c}50.0 \% \\
(55.5 \%)\end{array}$ & $\begin{array}{c}31.2 \% \\
(33.3 \%) \\
\end{array}$ & $\begin{array}{c}37.5 \% \\
(33.3 \%)\end{array}$ & $\begin{array}{c}6.2 \% \\
(11.1 \%) \\
\end{array}$ \\
\hline & $\begin{array}{l}\text { Medium < } \\
\text { high }\end{array}$ & $\begin{array}{c}37.5 \% \\
(33.3 \%) \\
\end{array}$ & $\begin{array}{c}43.8 \% \\
(44.4 \%) \\
\end{array}$ & $\begin{array}{c}37.5 \% \\
(33.3 \%) \\
\end{array}$ & $\begin{array}{c}68.8 \% \\
(77.8 \%) \\
\end{array}$ \\
\hline & High & $\begin{array}{c}6.2 \% \\
(11.1 \%)\end{array}$ & $\begin{array}{c}6.2 \% \\
(0)\end{array}$ & $\begin{array}{c}18.8 \% \\
(33.3 \%)\end{array}$ & $\begin{array}{c}6.2 \% \\
(0)\end{array}$ \\
\hline
\end{tabular}

A comparison of the estimates between the three groups shows no significant difference in the chosen values (Chi-squared values between 6.97 and 13.80, degrees of freedom=12 and $\mathrm{p}<0.05$ ). However, comparing the values for the two questionnaires, the results for all the participants show that there is a significant difference for group A and C and for 2018. Participants of group A tended to lower their forecasts, those of group $\mathrm{C}$ to increase it. The reason for this difference in the reactions will be explored in the following sections. No difference was found in the forecasts of 2014 or in the estimates of group B. The results for the experienced participants show that there is a significant difference between the two questionnaires only for group $\mathrm{C}$ for both years. This indicates that for group A the difference of the stated forecasts between the questionnaires was caused by the non-experienced participants.

\footnotetext{
* Significant difference between questionnaires 1 and 2 for group A, cost estimate for 2018, all participants, chisquared $=3.91$, degree of freedom $=1, \mathrm{p}<0.05$.

$\dagger$ Significant difference between questionnaires 1 and 2 for group $\mathrm{C}$ for all participants for 2018, chi-squared=4.59; for experienced participants 2014 chi-squared $=7.04$, for 2018 chi-squared $=6.60$; degree of freedom $=1, \mathrm{p}<0.05$.
} 


\subsection{Confidence levels}

This section discusses the participants' reactions to the different types of graphical display in the context of their confidence level. Figure 3 shows the percentage of participants in each group selecting particular confidence levels for their 2014 and 2018 estimates. Again, no significant difference was found between the responses from the experienced participants and the others so there was no evidence that the experienced users of the graphs were more confident in their forecasts than the inexperienced users. In general, it would be expected that the participants would be less confident with their 2018 cost estimate than with their estimate for 2014. However, this expectation was not confirmed for either of the groups (chi-squared values between 0.19 and 5.18 for the whole set of participants and between 1.48 and 2.72 for the experienced participants, degrees of freedom $=1, \mathrm{p}<0.05)$.

\section{Group A}
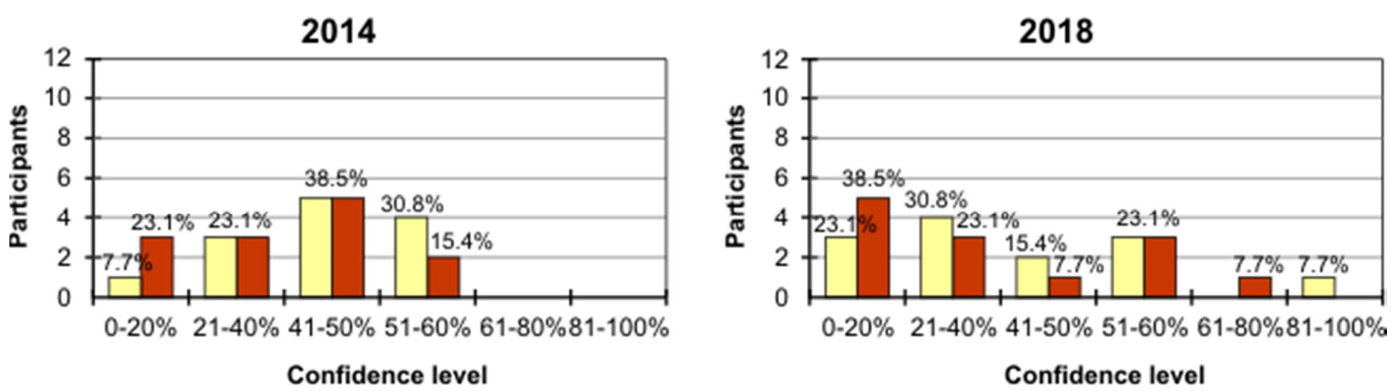

\section{Group B}
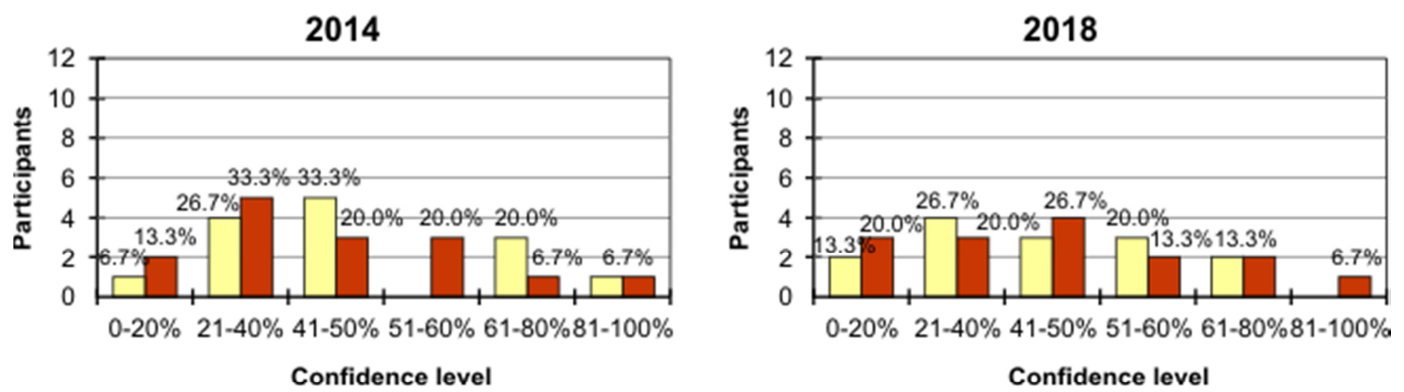

Group C
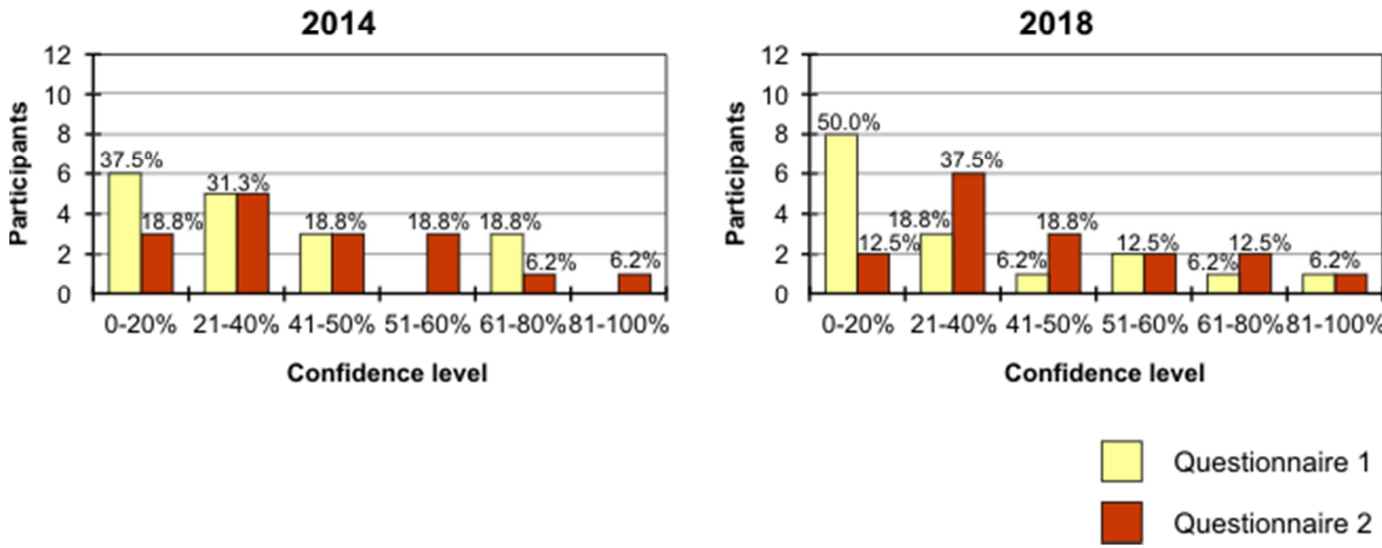

Figure 3: Confidence levels for each group in comparison

Table 4 depicts the number of participants choosing particular confidence levels in percentage for all the participants and for the experienced participants in brackets. 
Table 4: Confidence levels by group in comparison between whole set and experienced subset of participants

\begin{tabular}{|c|c|c|c|c|c|}
\hline & \multirow{2}{*}{$\begin{array}{l}\text { Year } \\
\text { Questionnaire }\end{array}$} & \multicolumn{2}{|c|}{2014} & \multicolumn{2}{|c|}{2018} \\
\hline & & 1 & 2 & 1 & 2 \\
\hline \multirow{6}{*}{ Group A } & $0-20 \%$ & $\begin{array}{c}7.7 \% \\
(10.0 \%)\end{array}$ & $\begin{array}{c}23.1 \% \\
(30.0 \%)\end{array}$ & $\begin{array}{c}23.1 \% \\
(20.0 \%)\end{array}$ & $\begin{array}{c}38.5 \% \\
(20.0 \%)\end{array}$ \\
\hline & $21-40 \%$ & $\begin{array}{c}23.1 \% \\
(20.0 \%) \\
\end{array}$ & $\begin{array}{c}23.1 \% \\
(30.0 \%) \\
\end{array}$ & $\begin{array}{c}30.8 \% \\
(30.0 \%) \\
\end{array}$ & $\begin{array}{c}23.1 \% \\
(10.0 \%) \\
\end{array}$ \\
\hline & $41-50 \%$ & $\begin{array}{c}38.5 \% \\
(40.0 \%) \\
\end{array}$ & $\begin{array}{c}38.5 \% \\
(20.0 \%) \\
\end{array}$ & $\begin{array}{c}15.4 \% \\
(20.0 \%) \\
\end{array}$ & $\begin{array}{c}7.7 \% \\
(10.0 \%) \\
\end{array}$ \\
\hline & $51-60 \%$ & $\begin{array}{c}30.8 \% \\
(30.0 \%)\end{array}$ & $\begin{array}{c}15.4 \% \\
(20.0 \%))\end{array}$ & $\begin{array}{c}23.1 \% \\
(20.0 \%)\end{array}$ & $\begin{array}{c}23.1 \% \\
(20.0 \%)\end{array}$ \\
\hline & $61-80 \%$ & $\begin{array}{c}0 \\
(0)\end{array}$ & $\begin{array}{c}0 \\
(0)\end{array}$ & $\begin{array}{c}0 \\
(0)\end{array}$ & $\begin{array}{c}7.7 \% \\
(10.0 \%)\end{array}$ \\
\hline & $81-100 \%$ & $\begin{array}{c}0 \\
(0) \\
\end{array}$ & $\begin{array}{c}0 \\
(0) \\
\end{array}$ & $\begin{array}{c}7.7 \% \\
(10.0 \%) \\
\end{array}$ & $\begin{array}{c}0 \\
(0) \\
\end{array}$ \\
\hline \multirow{6}{*}{ Group B* } & $0-20 \%$ & $\begin{array}{c}6.7 \% \\
(0)\end{array}$ & $\begin{array}{l}13.3 \% \\
(8.3 \%) \\
\end{array}$ & $\begin{array}{l}13.3 \% \\
(8.3 \%)\end{array}$ & $\begin{array}{c}20.0 \% \\
(25.0 \%)\end{array}$ \\
\hline & $21-40 \%$ & $\begin{array}{c}26.7 \% \\
(33.3 \%) \\
\end{array}$ & $\begin{array}{c}33.3 \% \\
(41.7 \%) \\
\end{array}$ & $\begin{array}{c}26.7 \% \\
(33.3 \%) \\
\end{array}$ & $\begin{array}{c}20.0 \% \\
(25.0 \%) \\
\end{array}$ \\
\hline & $41-50 \%$ & $\begin{array}{c}33.3 \% \\
(33.3 \%) \\
\end{array}$ & $\begin{array}{c}20.0 \% \\
(16.7 \%) \\
\end{array}$ & $\begin{array}{c}20.0 \% \\
(25.0 \%) \\
\end{array}$ & $\begin{array}{c}26.7 \% \\
(25.0 \%) \\
\end{array}$ \\
\hline & $51-60 \%$ & $\begin{array}{c}0 \\
(0) \\
\end{array}$ & $\begin{array}{c}20.0 \% \\
(16.7 \%) \\
\end{array}$ & $\begin{array}{c}20.0 \% \\
(16.7 \%) \\
\end{array}$ & $\begin{array}{c}13.3 \% \\
(16.7 \%) \\
\end{array}$ \\
\hline & $61-80 \%$ & $\begin{array}{c}20.0 \% \\
(16.7 \%)\end{array}$ & $\begin{array}{c}6.7 \% \\
(8.3 \%) \\
\end{array}$ & $\begin{array}{l}13.3 \% \\
(8.3 \%) \\
\end{array}$ & $\begin{array}{c}13.3 \% \\
(0)\end{array}$ \\
\hline & $81-100 \%$ & $\begin{array}{c}6.7 \% \\
(8.3 \%) \\
\end{array}$ & $\begin{array}{c}6.7 \% \\
(8.3 \%) \\
\end{array}$ & $\begin{array}{c}0 \\
(0) \\
\end{array}$ & $\begin{array}{c}6.7 \% \\
(8.3 \%) \\
\end{array}$ \\
\hline \multirow{6}{*}{ Group $\mathbf{C}^{\dagger}$} & $0-20 \%$ & $\begin{array}{l}31.3 \% \\
(33.3 \%)\end{array}$ & $\begin{array}{c}18.8 \% \\
(22.2 \%)\end{array}$ & $\begin{array}{c}50.0 \% \\
(66.7 \%)\end{array}$ & $\begin{array}{c}12.5 \% \\
(11.1 \%)\end{array}$ \\
\hline & $21-40 \%$ & $\begin{array}{c}31.3 \% \\
(11.1 \%) \\
\end{array}$ & $\begin{array}{c}31.3 \% \\
(22.2 \%) \\
\end{array}$ & $\begin{array}{c}18.8 \% \\
(0) \\
\end{array}$ & $\begin{array}{c}37.5 \% \\
(44.4 \%) \\
\end{array}$ \\
\hline & $41-50 \%$ & $\begin{array}{c}18.8 \% \\
(22.2 \%)\end{array}$ & $\begin{array}{c}18.8 \% \\
(11.1 \%)\end{array}$ & $\begin{array}{c}6.2 \% \\
(0)\end{array}$ & $\begin{array}{c}18.8 \% \\
(11.1 \%)\end{array}$ \\
\hline & $51-60 \%$ & $\begin{array}{c}0 \\
(0) \\
\end{array}$ & $\begin{array}{c}18.8 \% \\
(22.2 \%)\end{array}$ & $\begin{array}{c}12.5 \% \\
(11.1 \%)\end{array}$ & $\begin{array}{c}12.5 \% \\
(11.1 \%)\end{array}$ \\
\hline & $61-80 \%$ & $\begin{array}{c}18.8 \% \\
(33.3 \%) \\
\end{array}$ & $\begin{array}{c}6.2 \% \\
(11.1 \%) \\
\end{array}$ & $\begin{array}{c}6.2 \% \\
(11.1 \%) \\
\end{array}$ & $\begin{array}{c}12.5 \% \\
(11.1 \%) \\
\end{array}$ \\
\hline & $81-100 \%$ & $\begin{array}{c}0 \\
(0)\end{array}$ & $\begin{array}{c}6.2 \% \\
(11.1 \%)\end{array}$ & $\begin{array}{c}6.2 \% \\
(11.1 \%)\end{array}$ & $\begin{array}{c}6.2 \% \\
(11.1 \%)\end{array}$ \\
\hline
\end{tabular}

The introduction of contextual information in questionnaire 2 resulted in a significant change only for group $\mathrm{C}$; those participants became more confident. A possible reason can be seen in the fact that the most frequently stated confidence levels for group $\mathrm{C}$ in questionnaire 1 was $0-20 \%$ and thus were significantly lower than the ones of groups A and B. A more detailed analysis of the participants reasoning will be discussed in Section 4.3.

\footnotetext{
* Significant difference between questionnaires 1 and 2 for group B in 2014, for all participants chi-squared $=4.92$, experienced participants chi-squared $=4.08$, degree of freedom $=1, \mathrm{p}<0.05$.

${ }^{\dagger}$ Significant difference between questionnaires 1 and 2 for group C, 2014: all participants chi-squared=5.98, experience participants chi-squared $=4.87 ; 2018$ : all participants chi-squared $=5.93$, experience participants chi-squared $=8.57$, degree of freedom $=1, \mathrm{p}<0.05$.
} 


\subsection{Reasoning for estimates}

To understand the rationale used by the participants in providing their estimates, the narrative answers were examined closely. The reasons given for their estimates have been categorised as follows: lack of information to enable a good estimate to be made, the medium point being judged as the most likely to occur, a conservative answer which includes the highest cost estimate or a point between medium and high, the subjective interpretations of the future development of the world economy, and the existence of uncertainty. Table 5 shows the values per category for all the participants with those for the experienced participants in brackets.

Table 5 Linguistic explanations per category

\begin{tabular}{|l|c|c|c|c|c|c|}
\hline & \multicolumn{2}{|c|}{ Group A $^{* \dagger}$} & \multicolumn{2}{c|}{ Group B $^{\ddagger}$} & \multicolumn{2}{c|}{ Group C $^{\text {\$** }^{* *}}$} \\
\hline Questionnaire & $\mathbf{1}$ & $\mathbf{2}$ & $\mathbf{1}$ & $\mathbf{2}$ & $\mathbf{1}$ & $\mathbf{2}$ \\
\hline \multirow{2}{*}{ more information } & $15.4 \%$ & 0 & $20.0 \%$ & $6.7 \%$ & $12.5 \%$ & 0 \\
& $(20.0 \%)$ & $(0)$ & $(25.0 \%)$ & $(10.0 \%)$ & $(22.2 \%)$ & $(0)$ \\
\hline \multirow{2}{*}{ medium } & $38.4 \%$ & $38.4 \%$ & $20.0 \%$ & $20.0 \%$ & $50.0 \%$ & $6.2 \%$ \\
& $(30.0 \%)$ & $(30.0 \%)$ & $(0)$ & $(0)$ & $(33.3 \%)$ & $(11.1 \%)$ \\
\hline \multirow{2}{*}{ conservative } & $15.4 \%$ & $15.4 \%$ & $33.3 \%$ & $46.7 \%$ & $12.5 \%$ & $12.5 \%$ \\
& $(20.0 \%)$ & $(20.0 \%)$ & $(41.7 \%)$ & $(58.3 \%)$ & $(22.2 \%)$ & $(22.2 \%)$ \\
\hline \multirow{2}{*}{ world economy } & $15.4 \%$ & $46.2 \%$ & $13.3 \%$ & $13.3 \%$ & $18.8 \%$ & $25.0 \%$ \\
& $(10.0 \%)$ & $(50.0 \%)$ & $(16.7 \%)$ & $(16.7 \%)$ & $(11.1 \%)$ & $(11.1 \%)$ \\
\hline \multirow{2}{*}{ uncertainty } & $15.4 \%$ & 0 & $13.3 \%$ & $13.3 \%$ & $6.3 \%$ & $75.0 \%$ \\
& $(20.0 \%)$ & $(0)$ & $(20.0 \%)$ & $(16.7 \%)$ & $(11.1 \%)$ & $(55.6 \%)$ \\
\hline
\end{tabular}

The additional contextual information in questionnaire 2 was found to influence the reasoning of the participants of group A and C. Thus, for group B the graphical display had a higher influence on the chosen cost forecast than the additional contextual information. The same results were found for the experienced participants.

A comparison of the three groups shows a significant difference between the reasoning of the three groups for all participants only for questionnaire 2 . This means that the combination of contextual information and different graphical displays triggers the decision maker to interpret the given information differently. In contrast, for the experienced participants, the only significant difference between was found in the comparison of group A and B, questionnaire 2. In other words, the knowledge of the experienced decision makers outweighs the influence of the displaying approach.

Without the contextual information, participants of group A (three point trend graph) and C (fan diagram) chose a medium value for their forecast and group B (bar chart) chose a conservative value. With the introduction of additional contextual information, participants of group A were more likely to state the influence of the world economy on their cost forecast, group B chose a conservative forecast and participants of group $\mathrm{C}$ to state uncertainty as an important reason for

\footnotetext{
${ }^{*}$ Significant difference between questionnaires 1 and 2 for group A, chi-squared $=4.00$ for all participants and 6.67 for experienced participants, degree of freedom $=1, \mathrm{p}<0.05$.

$\dagger$ Significant difference between groups A and B for questionnaire 2, all participants and experienced participants chisquared $=9.96$, degree of freedom $=4, \mathrm{p}<0.05$.

$\$$ Significant difference between groups B and C for questionnaire 2, all participants chi-squared=9.88, degree of freedom $=4, \mathrm{p}<0.05$.

$\S$ Significant difference between questionnaires 1 and 2 for group $C$, chi-squared $=7.59$ for all participants and 5.67 for experienced participants, degree of freedom $=1, \mathrm{p}<0.05$.

** Significant difference between groups $\mathrm{A}$ and $\mathrm{C}$ for questionnaire 2, all participants chi-squared=11.88, degree of freedom $=4, \mathrm{p}<0.05$.
} 
their cost estimate. Thus, the fan diagram can be identified as the graphical approach that is most likely to trigger the decision maker to recognise the uncertainty inherent in the cost forecast.

\section{Discussion}

The results of this empirical study show the effect that different approaches to displaying forecasting information can have on its perception and interpretation. Participants in all groups were most likely to choose a cost forecast that was medium or between medium and high. Participants of group A were more likely to have a confidence level around 50\% and state the medium value as the reason for their decision. The additional contextual information caused these decision makers to lower their forecast and change their reasoning to that of the influence of the world economy. The confidence levels stayed unchanged. For the experienced participants of that group, these values were similar to that of the novices; however the additional contextual information had no influence on their answers.

Participants of group B were most likely to choose a confidence level around $40 \%$ and state a conservative value as the reason for their decision. The additional contextual information produced no change for this group. The level of experience had no influence on the participants of that group.

Participants of group C were most likely to have a confidence level around $20 \%$ and state the medium value as the reason for their decision. The additional contextual information triggered those participants to increase their confidence levels and to identify uncertainty as a main reason for their cost forecast. The experienced participants of this group had similar results; however, the additional contextual information triggered them to lower their cost forecast.

The identification of the world economy as a possible influence on the participants' decision (particularly of group A) can be classified as an uncertainty which is outside of the decision maker's control or influence (also described as exogenous uncertainty [89]). Therefore, the three point trend forecast prompted the decision makers to include this particular type of exogenous uncertainty in their choice. Thus, it can be used as a displaying approach for cost forecasting scenarios which are mainly influenced by this type of uncertainty.

Despite the uncertainty inherent in the given information point estimates were common, even when the existence of uncertainty was identified. Most of the participants that stated range estimates were experienced in the field (the only exception was observed in group $\mathrm{C}$ where one inexperienced participant gave a range estimate). This indicates that decision makers tend to simplify their cost forecast when including the information in their decision, a finding which is consistent with those of earlier studies e.g. Dawes [46] and Simon [90]. Decision makers tend to simplify the level of uncertainty from a possible range of future outcomes to a limited set. This is an important point especially in the context of inducing decision makers to consider uncertainty in their choices. A decision maker in reality is not only limited in the amount of information he/she can ascertain and its complexity but also on the level of uncertainty he/she is able to consider.

Particularly for group $\mathrm{C}$, the additional contextual information triggered the participants to identify the uncertainty inherent in the cost forecast. However, drawing the conclusion that more contextual information would lead to an enhanced consideration of uncertainty is not applicable as human beings are bounded in the amount of information they can perceive and include in their decision process [86-88]. Shanteau [91] provides a review of experimental work that focuses on the use of given information in the decision process by both experts and non-experts. It was not the aim of this paper to identify the optimal amount of information given to a decision maker nor was any such conclusion found in the literature. Further research needs to be carried out in this area.

The potential limitations of this empirical study are connected mainly to the decision making environment. Given the fact that the participants of the experiment were drawn out of their usual 
original organisational and political environment and put into the laboratory environment of the workshop, not all the impacts of possible influencing factors can be simulated [81]. Some of the motivations to produce a correct estimate may simply not be possible to include in the experiment situation. Those motivations can be rewards for an accurate forecast as well as those related to the organisational conditions the decision maker works in [81]. As the experiment was carried out in the professional environment of a workshop connected with the topic those limitations can be accounted as only partly applicable. The participants were experts on the topic of cost forecasting and the interpretation of cost forecasts belonged to their professional work.

\section{Conclusions and future research}

Out of the three displays tested, the fan diagram was the most effective in raising awareness of the associated uncertainty. The participants presented with the fan diagram were in general less confident in their estimates, were more likely to state a range forecast, and identified uncertainty as a major factor on the cost estimation outcome. Furthermore, information describing the context forms an important aspect to raise the decision maker's awareness of the uncertainty connected to the decision.

The results of this empirical study have important implications for further research, particularly in the area of pricing decisions which are based on the cost forecast. To model the pricing-decision process it is important to understand how the decision maker interprets the cost forecast, the context of the decision and the uncertainty associated with the project. Furthermore, this decision may be influenced by additional uncertainties connected to the pricing environment. The understanding and comprehension of uncertainty in this domain is regarded as essential for a successful strategic progression of a company particularly within a competitive environment. For this research, a FAN diagram is regarded as the most suitable method for displaying uncertain costing information and supporting the decision maker's awareness and interpretation of uncertainty.

Future research will focus on the uncertainty arising from the existence of competition and its influence on the pricing decision. In addition to the empirical work presented in this paper, this will give a more elaborate and comprehensive understanding of the decision maker's reaction to different levels and characteristics of uncertainty in a pricing decision problem. This understanding should enable practitioners to make better decisions and to price their products and service projects more accurately.

\section{Acknowledgements:}

The authors gratefully acknowledge the support provided by the Innovative design and Manufacturing Research Centre (IdMRC) at University of Bath, UK funded by the Engineering and Physical Science Research Council (EPSRC) under Grant No. GR/R67507/01 for the research reported in this paper. Furthermore, the authors would like to thank the Society for Cost Analysis and Forecasting (SCAF), in particular Arthur Griffiths and Max Murray-Brooks, for their help and support in this experimental study.

\section{References:}

[1] V. Tang "Corporate Decision Analysis: An Engineering Approach", PhD Thesis, 2006, Massachussetts Institute of Technology, Engineering Systems Division.

[2] D.P. Thunnissen. "Uncertainty Classification for the Design and Development of Complex Systems". In PMC2003 - 3rd Annual Predictive Methods Conference. Newport Beack, California, USA, 2003, 16-17 June. 
[3] Y.M. Goh "The Incorporation of Uncertainty into Engineering Knowledge Managament", 2005, University of Bristol, Department of Mechanical Engineering.

[4] N.P. Suh, "Axiomatic Design Advances and Applications". 2001 (Oxford University Press, New York, NY, USA).

[5] Y.M. Goh; L.B. Newnes; A.R. Mileham; C.A. McMahon; and M.E. Saravi, "Uncertainty in Through-Life Costing - Review and Perspectives". IEEE Transactions on Engineering Management, 2010, accepted, pp.

[6] J. Daahuizen; P. Badke-Schaub; and S.M. Batill. "Dealing with uncertainty in Design Practice: Issues for Designer-centered Methodology". In ICED09 - International Conference on Engineering Design. Stanford, CA, USA, 2009, 24-27 August.

[7] M. Abdellaoui and J.D. Hey, "Advances in Decision Making Under Risk and Uncertainty". 2008 (Springer-Verlag, Berlin-Heidelberg).

[8] Y.M. Goh; L.B. Newnes; C. McMahon; A. Mileham; and C. Paredis. "A framework for considering uncertainty in quantitative Life Cycle cost estimation". In ASME IDETC/CIE International Design Engineering Technical Conferences \& Computers and Information in Engineering Design. San Diego, USA, 2009, 30 August - 2 September.

[9] J.A. Erkoyuncu; R. Roy; E. Shehab; and P. Wardle. "Uncertainty challenges in service cost estimation for product-service systems in the aerospace and defence industries". In CIRP Design Conference 2009 - Industrial Product-Service Systems (IPS2) Conference. Cranfield, UK, 2009, 30-31 March.

[10] P. Jovanovic, "Application of sensitivity analysis in investment project evaluation under uncertainty and risk". International Journal of Project Management, 1999, 17(4), pp. 217222.

[11] D. Hastings and H. McManus. "A Framework for Understanding Uncertainty and its Mitigation and Exploitation in Complex Systems". In MIT Engineering Systems Symposium. Cambridge, Massachusetts, 2004, March 2004.

[12] F. Farhangmehr and I.Y. Tumer. "Optimal Risk-based Integrated Design (ORBID) for Multidisciplinary Complex Systems". In ICED'09 - 17th International Conference on Engineering Design. Stanford, USA, 2009, 24-27 August.

[13] D. Dubois; H. Fargier; and R. Sabbadin. "Qualitative Decision Rules under Uncertainty". In ECSQARU - 7th European Conference on Symbolic and Quantitative Approaches to Reasoning with Uncertainty Aalborg, Denmark 2003, 2-5 July.

[14] H.-J. Zimmermann, "An application-oriented view of modeling uncertainty". European Journal of Operational Research, 2000, 122(2000), pp. 190-198.

[15] A. Langridge, "Uncertainty", In SCAF Workshop on "Defence Indecision"(Editor^Editors). 2010: Bristol, UK.

[16] G. Zotteri and M. Kalchschmidt, "Forecasting practices: Empirical evidence and a framework for research". International Journal of Production Economics, 2007, 108(1-2), pp. 84-99.

[17] M. Kishk; A. Al-Hajj; R. Pollock; G. Aouad; N. Bakis; and M. Sun, "Whole life costing in construction", in The RICS Foundation Paper Series, 2003, (University of Salford Institutional Repository, London), pp. 1-39.

[18] D. Greves and B. Schreiber, "Engineering Costing Techniques in ESA". Last Update: 1995, Date available from http://www.esa.int/esapub/bulletin/bullet81/greve81.htm. 
[19] C. Speier, "The Influence of Information Presentation Formats on Complex Task Decisionmaking Performance". International Journal of Human-Computer Studies, 2006, 64(2006), pp. 1115-1131.

[20] C. Speier and M.G. Morris, "The Influence of Query Interface Design on Decision-making Performance". MIS Quarterly, 2003, 27, pp. 397-423.

[21] A.H. Willett, "The Economic Theory of Risk and Insurance". 1901 (Irwin Inc., Homewood, Il, USA).

[22] F. Knight, "The Place of Profit and Uncertainty in Economic Theory", in Risk, Uncertainty and Profit, 1921, (Harper Torchbooks, New York, USA), pp. 3-21.

[23] S. Samson; J.A. Reneke; and M.M. Wiecek, "A review of different perspectives on uncertainty and risk and an alternative modeling paradigm". Reliability Engineering \& System Safety, 2009, 94(2), pp. 558-567.

[24] G.A. Holton, "Defining Risk". Financial Analysts Journal, 2004, 60(6), pp. 19-25.

[25] J.P. Van der Sluijs; M. Craye; S. Funtowicz; P. Kloprogge; J. Ravetz; and J. Risbey, "Combining Quantitative and Qualitative Measures of Uncertainty in Model-Based Environmental Assessment: The NUSAP System". Risk Analysis: An International Journal, 2005, 25(2), pp. 481-492.

[26] C. Soanes, "The Oxford English Dictionary". Vol. XI, 2005 (Oxford University Press, Oxford, UK).

[27] L. Huyse and R.W. Walters, "Random Field Solutions Including Boundary Condition Uncertainty for the Steady-Stae Generalized Burgers Equation", 2001, Report, ICASE NASA Langley Research Center.

[28] T. Bedford and R. Cooke, "Probabilistic Risk Analysis: Foundations and Methods". 2001 (Cambridge University Press, Cambridge, UK).

[29] Y.M. Goh; C.A. McMahon; and J.D. Booker, "Development and characterisation of error functions in design". Research in Engineering Design, 2007, 18(3), pp. 129-149.

[30] D. Moens and D. Vandepitte, "Non-probabilistic approaches for non-deterministic dynamic FE analysis of imprecisely defined structures", In ISMA2004 - International Conference on Noise and Vibration Engineering(Editor^${ }^{\wedge}$ Editors). 2004: Leuven, Belgium. pp. 3095-3120.

[31] I.T. Dimov, "Monte Carlo Methods for Applied Scientists". 2008 (World Scientific, Singapore).

[32] J. Detemple and M. Rindisbacher, "Monte Carlo methods for derivatives of options with discontinuous payoffs". Computational Statistics \& Data Analysis, 2007, 51(7), pp. 33933417.

[33] N.B. Amor; S. Benferhat; D. Dubois; H. Geffner; and H. Prade, "Independence in Qualitative Uncertainty Frameworks". Proceedings of Principles of Knowledge Representation and Reasoning (KR'2000), 2000, pp. 235-246.

[34] P.N. Christensen; G.A. Sparks; and k.J. Kostuk, "A method-based survey of life cycle costing literature pertinent to infrastructure design and renewal". Canadian Journal of Civil Engineering, 2005, 32(2005), pp. 250-259.

[35] Y. Asiedu and P. Gu, "Product life cycle cost analysis: state of the art review". International Journal of Production Research, 1998, 36(4), pp. 883-908. 
[36] D.G. Woodward, "Use of sensitivity analysis in build-own-operate-transfer project evaluation". International Journal of Project Management, 1995, 13(4), pp. 239-246.

[37] D. Dubois; H. Prade; and R. Sabbadin, "Decision-theoretic foundations of qualitative possibility theory". European Journal of Operational Research, 2001, 128(3), pp. 459-478.

[38] Q. Jiang and C.-H. Chen, "A multi-dimensional fuzzy decision support strategy". Decision Support Systems, 2005, 38(4), pp. 591-598.

[39] D. Dubois and H. Prade, "Fuzzy Sets, Probability and Measurement". European Journal of Operational Research, 1989, 40(2), pp. 20.

[40] L.A. Zadeh, "Fuzzy Sets". Information and Control, 1965, 8(1965), pp. 338-353.

[41] E. Gerber. "Prototyping: Facing Uncertainty Through Small Wins". In ICED'09 International Conference on Engineering Design. Stanford, USA, 2009, 24-27 August.

[42] M.E.P. Seligman, "Learned optimism: How to change your mind and your life". 2006 (Vintage Books, New York, USA).

[43] E. Deci and R. Ryan, "The Support of Autonomy and the Control of Behavior". Journal of Personality and Social Psychology, 1987, 53(1987), pp. 1024-1037.

[44] S.E. Taylor and J.D. Brown, "Illusion and Well-Being: A Social Psychological Perspective on Mental Health". Psychological Bulletin, 1988, 103(2), pp. 193-210.

[45] R.B. Cialdini, "Influence: The Psychology of Persuasion". 3rd ed, 2007 (Harper Collins Publishers, New York, NY, USA).

[46] R.M. Dawes, "Rational Choice in an Uncertain World". 1988 (Harcourt Brace Jovanovich Publishers, San Diego, CA, USA).

[47] D.E. Bell, "Disappointment in Decision Making under Uncertainty". Operations Research, 1985, 33(1), pp. 1-27.

[48] G. Loomes and R. Sugden, "Regret Theory: An Alternative Theory of Rational Choice Under Uncertainty". The Economic Journal, 1982, 92(368), pp. 805-824.

[49] D.E. Bell, "Regret in Decision Making under Uncertainty". Operations Research, 1982, 30(5), pp. 961-981.

[50] T. Connolly and M. Zeelenberg, "Regret in Decision Making". Current Directions in Psychological Science, 2002, 11(6), pp. 212-216.

[51] N. Schwarz, "Emotion, Cognition, and Decision Making". Cognition and Emotion, 2000, 14(1), pp. 433-440.

[52] E.J. Langer, "The Illusion of Control". Journal of Personality and Social Psychology, 1975, 32(2), pp. 311-328.

[53] E.J. Langer, "The Psychology of Chance". Journal of Social Theory and Behaviour, 1975, 7(1975), pp. 185-207.

[54] E.J. Langer and J. Roth, "Heads I win, tails is chance: The Illusion of control is a function of the sequence of outcomes in a purely chance task". Journal of Personality and Social Psychology, 1975, 32(1975), pp. 951-955.

[55] S. Lichtenstein; B. Fischhoff; and L.D. Phillips, "Calibration of probabilities: The state of the art to 1980", in Judgement under Uncertainty: Heuristics and biases, 1982, (Cambridge University Press, Cambridge, UK), pp. 306-334. 
[56] G.F. Pitz, "Subjective probability distributions for imperfectly known quantities", in Knowledge and cognition, 1974, (Lawrence Erlbaum, Oxford, UK), pp. 29-42.

[57] M. Alpert and H. Raiffa, "A progress report on the training of probability assessors", in Judgement under Uncertainty: Heuristics and biases, 1982, (Cambridge University Press, Harvard University, USA), pp. 294-305.

[58] M.S. Phadke, "Quality Engineering Using Robust Design". 1989 (Prentice Hall, Englewood Cliffs, NJ, USA).

[59] M. O'Connor and M. Lawrence, "An Examination of the Accuracy of Judgmental Confidence intervals in Time Series Forecasting". Journal of Forecasting, 1989, 8(1989), pp. 141-155.

[60] P. Giordani and P. Söderlind, "Inflation forecast uncertainty". European Economic Review, 2003, 47(6), pp. 1037-1059.

[61] J. Selvidge, "Assessing the extremes of probability distributions by the fractile method". Decision Science, 1980, 11(1980), pp. 493-502.

[62] R.C. Pickhardt and J.B.A. Wallace, "A study of the performance of subjective probability assessors". Decision Science, 1974, 5(1974), pp. 347-363.

[63] N. Harvey, "Improving judgement in forecasting", in Principles of forecasting: A handbook for researchers and practitioners, 2001, (Springer Science \& Business Media, New York, NY, USA).

[64] A. Tversky and D. Kahneman, "Judgment under Uncertainty: Heuristics and Biases". Science, 1974, 185(4157), pp. 1124-1131.

[65] M. Lawrence and S. Makridakis, "Factors Affecting Judgmental Forecasts and Confidence intervals". Organizational Behavior and Human Decision Processes, 1989, 43(2), pp. 172187.

[66] F. Bolger and N. Harvey, "Judging the probability that the next point in an observed timeseries will be below, or above, a given value". Journal of Forecasting, 1995, 14(7), pp. 597607.

[67] F.X. Diebold; A.S. Tay; and K.F. Wallis, "Evaluating density forecasts of in!ation: The survey of professional forecasters", in Cointegration, Causality, and Forecasting: A Festschrift in Honour of Clive W.J. Granger, 1997, (Oxford University Press, Oxford, UK).

[68] M. Lawrence; P. Goodwin; M. O'Connor; and D. Önkal, "Judgmental forecasting: A review of progress over the last 25 years". International Journal of Forecasting, 2006, 22(3), pp. 493-518.

[69] T.A. Brown, "An experiment on probabilistic forecasting", 1973, Report, The RAND Corp.

[70] S. Lichtenstein and B. Fischhoff, "Training for Calibration". Organizational Behavior and Human Performance, 1980, 26(1980), pp. 149-171.

[71] Z. Elouedi; K. Mellouli; and P. Smets, "Belief decision trees: theoretical foundations". International Journal of Approximate Reasoning, 2001, 28(2-3), pp. 91-124.

[72] D. Kahneman; P. Slovic; and A. Tversky, "Judgment under Uncertainty: Heuristics and biases". 1982 (Cambridge University Press, Cambridge, UK).

[73] M.G. Morgan and M. Henrion, "Uncertainty - A Guide to Dealing with Uncertainty in Quantitative Risk and Policy Analysis". 1990 (Cambridge University Press, Cambridge, UK). 
[74] N. Harvey and F. Bolger, "Graphs versus tables: Effects of data presentation format on judgemental forecasting". International Journal of Forecasting, 1996, 12(1), pp. 119-137.

[75] N.R. Sanders, "Accuracy of Judgmental Forecasts: A Comparison". Omega: International Journal of Management Science, 1992, 20(3), pp. 353-364.

[76] M. Cohen; J. Etner; and M. Jeleva, "Dynamic Decision Making When Risk Perception Depends on Past Experience", in Advances in Decision Making Under Risk and Uncertainty, 2008, (Springer-Verlag, Berlin), pp. 19-32.

[77] H. Kunreuther, "Mitigation disaster losses through insurance". Journal of Risk and Uncertainty, 1996, 12(1996), pp. 171-187.

[78] H. Courtney, "20/20 Foresight: Crafting Strategy in an Uncertain World ". 2001 (Harvard Business School Press,

[79] D.G. Ullmann. "Design: The Evolution of Information Punctuated by Decisions". In ICED'09 - International Conference on Engineering Design. Stanford, Ca, USA, 2009, 2427 August.

[80] E.R. Tufte, "The Visual Display of Quantitative Information". second ed, 2001 (Graphics Press LLC, Cheshire, USA).

[81] P. Goodwin and G. Wright, "Improving judgmental time series forecasting: A review of the guidance provided by research". International Journal of Forecasting, 1993, 9(1993), pp. 147-161.

[82] N.R. Sanders and L.P. Ritzman, "The need for contextual information and technical knowledge in judgemental forecasting". Journal of Behavioural Decision Making, 1992, 5(1992), pp. 39-52.

[83] A.S. Tay and K.F. Wallis, "Density Forecasting: A Survey". Journal of Forecasting, 2000, 19(4), pp. 235-254.

[84] G.W. Dickson; G. DeSanctis; and D.J. McBride, "Understanding the effectiveness of computer graphics for decision support: A cumulative experimental approach". Communications of the ACM, 1986, 29(1), pp. 40-47.

[85] M.N.K. Saunders; P. Lewis; and A. Thornhill, "Research methods for business students". 2009 (Financial Times Prentice Hall, Harlow, UK).

[86] E.-M. Sent, "The legacy of Herbert Simon in game theory". Journal of Economic Behavior \& Organization, 2004, 53(2004), pp. 303-317.

[87] R. Radner, "Costly and Bounded Rationality in Individual and Team Decision-making". Industrial and Corporate Change, 2000, 9(4), pp. 623-658.

[88] A. Rubinstein, "Modeling Bounded Rationality". 1998 (MIT Press, Cambridge).

[89] O. de Weck; C. Eckert; and J. Clarkson. "A Classification of Uncertainty for Early Product and System Design". In ICED'07 - International Conference on Engineering Design. Paris, France, 2007, 28-31 August 2007.

[90] H.A. Simon, "Models of Bounded Rationality: Behavioral Economics and Business Organization". Vol. 2, 1982 (Massachusetts Institute of Technology Press, Cambridge, Massachusetts, USA).

[91] J. Shanteau, "How Much Information Does An Expert Use? Is It Relevant?". Acta Psychologica, 1992, 81(1992), pp. 75-86. 
